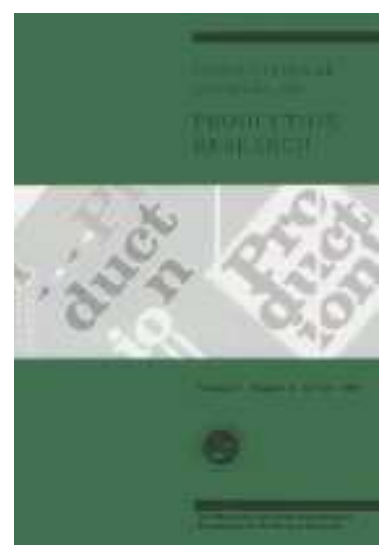

\title{
(20th ICPR) A Method to Align a Manufacturing Execution System with Lean Objectives
}

\begin{tabular}{|r|l|}
\hline Journal: & International Journal of Production Research \\
\hline Manuscript ID: & TPRS-2010-IJPR-1231 \\
\hline Manuscript Type: & Original Manuscript \\
\hline Author: & 12-Dec-2010 \\
\hline & $\begin{array}{l}\text { Complete List of Authors: } \\
\text { Industrial Management } \\
\text { Stockman, Kurt; University college of West-Flanders } \\
\text { Derammelaere, Stijn; University college of West-Flanders }\end{array}$ \\
\hline Keywords: & $\begin{array}{l}\text { MANUFACTURING INFORMATION SYSTEMS, LEAN } \\
\text { MANUFACTURING, VALUE STREAM MAPPING, CONTINUOUS } \\
\text { IMPROVEMENT }\end{array}$ \\
\hline Keywords (user): & ISA 95 \\
\hline
\end{tabular}

\section{SCHOLARONE Manuscripts}


A Method to Align a Manufacturing Execution System With Lean Objectives

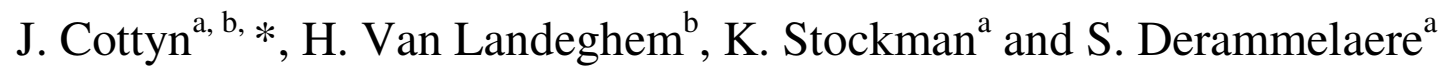 \\ ${ }^{a}$ University College of West-Flanders, Kortrijk, Belgium \\ ${ }^{\mathrm{b}}$ Department Industrial Management, Ghent University, Zwijnaarde, Belgium \\ *Corresponding author. Email: johannes.cottyn@ howest.be
}

The application of IT and Lean principles have long been seen as mutually exclusive, but both approaches are more and more claimed to be interdependent and complimentary. Real-time production information is crucial to make important business decisions. A Manufacturing Execution System (MES) can provide the necessary support during the Lean journey. MES can trigger, feed or validate the Lean decision making process by providing useful information. In addition, MES can maintain the process improvements by enforcing the standardized way of working. However, this is only possible when MES is aligned and is kept aligned to the Lean objectives. The MES processes must be included in the continuous improvement cycle to prevent them of becoming obsolete. In this work a method is proposed to analyze this alignment between Lean and MES. The Manufacturing Operations Management (MOM) framework provided by ISA 95 is believed to deliver the necessary components to identify and structure this alignment. Mapping MES and Lean activities onto the same framework brings valuable insights about their dependency. The analysis is explored through a case example. Preventing the system of becoming obsolete, by proposing standard model changes, is an important direction for further research.

Keywords: manufacturing, execution system, lean, ISA 95, continuous improvement, value stream map 


\section{Introduction}

Today's economic environment drives the adoption of strategic initiatives. In order to survive, companies need to get the most and the best out of the available resources. It is a continuous struggle to eliminate unnecessary production costs; improve manufacturing, process and business performance; increase throughput; reduce cycle times; maintain quality; etc. (Epicor 2008a). One of the strategic initiatives that helps manufacturers to remain competitive is Lean Manufacturing. Lean is a philosophy carrying the motto 'Doing more, with less!'. The concept of 'Lean' was first introduced by Womack et al. (1990) in order to describe the working philosophy and practices of the Japanese vehicle manufacturers and in particular the Toyota Production System (TPS). The essence of Lean thinking is specifying value and - by doing so - simultaneously uncovering waste. The initial concept of Lean was extended to five key principles by Womack and Jones (1996): Specify value; identify value streams; make value flow; let the customer pull value and pursue perfection. The ultimate goal is a production process without any of the seven deadly wastes: overproduction, waiting, transport, extra processing, inventory, motion and defects. However, as that situation is impossible to reach, Lean manufacturing is a continuous process towards perfection.

Lean thinking has evolved over time and has expanded beyond its origins in the automotive industry and its narrow definition around shop floor improvement (Hines et al. 2004). Lean is a philosophy and not a tool itself. Numerous tools and techniques - such as Single Minute Exchange of Dies (SMED), Six Sigma, Kanban, Value Stream Mapping (VSM), 5S, Total Quality Management (TQM), Theory of Constraints (TOC), Total Productive Maintenance (TPM), Business Process Management (BPM), Visual Management, etc. - can support the Lean transformation in order to identify, measure and remove waste, variability and overburden and deliver improvements in specific areas. SMED reduces waiting and overproduction by creating shorter machine setup times. VSM draws the actual material (and information) flow through the manufacturing resources and can reveal important areas for improvement. VSM can be considered as the starting point for any Lean transformation and its applicability is well documented in literature (Rother and Shook 1999, Braglia et al. 2006, Abdulmalek et al. 2007, Nash and Poling 2008, 
Mazur and Chen 2008, Serrano et al. 2008). Kanban reduces inventory by introducing a consumer pulled production system. The thoughtful application of the various approaches to exploit full Lean potential has had its share of attention (Shah and Ward 2003, Lasa et al. 2009). In order to avoid the misapplication of Lean manufacturing tools and metrics, Pavnaskar et al. (2003) introduce a classification scheme. With the classification scheme, manufacturing problems can be linked to the appropriate Lean manufacturing tools that will solve the problem.

As various tools and techniques exist to work towards the Lean goal, it is necessary to carefully plan and keep track of the Lean efforts. Value stream mapping results in the construction of a Lean roadmap. This work plan is a sequence of Lean practices that will be performed in order to evolve from the current (AS-IS) to the future (TO-BE) situation. A Lean planning system can document as well the progress as the impact of each step on carefully selected Lean metrics. This assessment tool structures the Lean journey by continuously updating the performance and the work plan. Lean metrics are a set of performance measures for Lean manufacturing. Examples are process throughput, total manufacturing lead time, labour productivity, Overall Equipment Effectiveness (OEE), etc. Many studies define their own metrics by performing some sort of statistical analysis on survey data. Shah and Ward (2007) use a feature extraction method to determine adequate measures of Lean production. Ray et al. (2006) developed a Lean index for the wood products industry. The study demonstrates that the statistical methodology of factor analysis can be used to develop a quantitative definition and assessment of the concept of 'leanness' for any wood processing company. The impact of typical Lean activities on the features of a Lean environment and the Lean performance metrics are presented by Duque et al. (2007). Mejabi (2003) proposes a framework for a Lean planning system that can be used to monitor and quantify the continuous improvement efforts.

To be able to pinpoint improvement opportunities and assess the progress, (historical and real-time) information must be available (Aberdeen 2005). That is why manufacturers see a greater need to adopt, upgrade or expand their business IT solutions. For example, Enterprise Resource Planning (ERP) software maintains important business data and supports the administrative processes. Product Lifecycle Management (PLM) software guides the product through the different stages of its 
lifecycle. Collecting, maintaining and updating the business data in support of the business processes, is important for daily operations. But additionally, in-depth business visibility can be created by adding an appropriate level of intelligence. Carefully designed windows on the data can extract useful information, that is not visible at first sight. This Business Intelligence (BI) can expose the necessary opportunities to steer the business decision-making process.

Figure 1 shows how this idea can be extended to the manufacturing level. Real-time production information is crucial to the daily manufacturing operations. But additionally, Manufacturing Intelligence (MI) can provide the necessary visibility for the continuous improvement efforts within the production facility. Different kinds of software tools can analyze the real-time data and turn them into valuable knowledge to optimize manufacturing operations. Production departments have always favored the development of custom-made software applications for manufacturing operations support, due to a lack of attention paid by information system specialists to the shop floor. However, the difficulty of integrating multiple point systems has brought software providers to package multiple execution management components into single and integrated solutions (Saenz et al. 2009). These systems, commonly referred to as Manufacturing Execution System (MES), provide a common user interface and data management system. The emergence of functional (MESA 1997) and integration (ISA 2000) standards defined the role of those systems within Computer Integrated Manufacturing (CIM) more closely. That has proven to be an important step from custom-made to pseudo-standard (configured) MES solutions.

In this work the necessary alignment between strategic objectives and operational support is described. In particular, the role of manufacturing operations management (MOM) during the Lean journey is emphasized. Both approaches pursue the same objectives and - if properly combined - are seen as mutually supportive. MOM can trigger, feed or validate the Lean decision making process by providing useful information. In addition, MOM can maintain the process improvements by enforcing the standardized way of working. On the other hand, MOM processes most be included in the continuous improvement cycle to prevent them of becoming obsolete. Section 2 provides a general overview of the combination of the Lean philosophy and the use of Information Technology (IT). The MOM framework 
provided by the ISA 95 standard is believed to deliver the necessary components to structure the alignment between MES and Lean. Section 3 describes the method for this alignment, in as well green- as brownfield projects. The proposed method is explored by a case example in section 4 . Section 5 concludes and mentions further research.

\section{Continuous Improvement \& IT}

The application of IT and Lean principles have long been seen as mutually exclusive. Lean advocates have the idea of putting in place a simplified information management system (Houy 2005). They consider that organizations based on continuous flow should limit information needs to local communication between upstream and downstream production units. In their view, it is preferable for employees to search for the information they need, as and when they need it, rather than configuring software to provide them with information that is repeated at predetermined times. Womack gives the following idea about information management: "Piling up information in a large inventory is as bad - maybe worse - than piling up large inventories of products." Information must be sent in small batches at a high frequency instead of large batches infrequently. System failures must be made immediately visible, so that they can be treated directly. Manual systems - such as the labelling system (Kanban), the andon cord and others - are more suitable because they are harder to ignore and force immediate action. Hicks (2007) describes the application of the Lean philosophy on IT systems in more detail. Within the proposed context of Lean Information Management, the seven deadly wastes are projected on the use of IT systems.

However, both approaches are more and more claimed to be interdependent and complimentary (Epicor 2008b, Riezebos et al. 2009). A Lean approach to high product mix, shared production assets and volatile demand scenario's are far from ideal. Kanban cards and heijunka boards become unmanageable. Calculating raw material, work in process, finished goods inventories, etc. can no longer be based on simple rules of thumb and experimental design. Here is where IT comes in handy. Complex issues can easily be dealt with in real-time. For example, Wan et al. (2007) describe a web-based Kanban system for job dispatching, tracking and performance monitoring. Lean IT solutions can also connect with suppliers, for example to include 
them in Kanban loops. The legal provisions in regulated industries (ex. food, pharmaceutical) require tracing functionality to link each finished product to its raw materials and processing steps. Without IT support, this task would be impossible to achieve. The human factor plays a crucial role when it comes to process improvements. But it is also very important to maintain those accomplished improvements. IT is seen as an enabler of the implemented improvements. Bell (2005) and Rio (2005) describe IT as the ideal solution to enforce standard work procedures. Ward and Zhou (2006) concluded that IT integration facilitates the implementation and the use of effective Lean/JIT practices.

\subsection{Continuous improvement - the role of MES}

Some research has already been done on the combination between the Lean Production System and Enterprise Resource Planning (ERP) (Goddard 2003). New technologies - such as SOA - enable the development of software systems that are able to support the requirements of Lean information management (Pfadenhauer et al. 2006). These MES systems can be flexible enough to accommodate the continuous improvement philosophy of a Lean environment. The (near) real-time information flow of the MES looks like a better fit for Lean than the batch oriented ERP systems. No previous research on this topic has been found, but software vendors already anticipate the Lean MES story. Stand-alone applications are already developed to automate and support Lean practices, such as E-Kanban, Six Sigma programs, Visual Management screens, Key Performance Indicators generators (KPI), etc. More and more MES software vendors have some Lean support incorporated. Every product folder has some reference to the Lean philosophy (Siemens 2007, GE Fanuc 2009). It must be that there is need for a MES that supports the Lean philosophy. In its Plantto-Enterprise (P2E) model, the Manufacturing Enterprise Solution Association (MESA) shows how strategic initiatives are linked to the shop floor within the entire enterprise IT system (MESA 2008). The model depicts the generation of information at the most basic value adding process levels of the plant and how this information supports and is supported by enterprise business application processes and longer term strategic initiatives. The importance of a well established manufacturing operations layer to create the necessary real-time manufacturing visibility is emphasized. MESA published manufacturing guidebooks for each strategic initiative they defined. Lean manufacturing is one of them (MESA 2010). However, a study of 
AMR (Masson and Jacobson 2007) shows a limited adoption of Lean IT so far. Ease of deployment and use remains a barrier to the adoption of Lean software on the shop floor. There is still room for innovators, for example to provide much-needed analytical workbenches on top of real-time data collection. A functionality that - in our opinion - is part of (or connected to) the presented MOM framework and can be aligned with MES software.

The continuous improvement philosophy of Lean (kaizen) can be supported by the Manufacturing Intelligence (MI) incorporated in MES. DMAIC (Define-MeasureAnalyze-Improve-Control) is a structured and disciplined approach to process improvement and is part of the Six Sigma methodology. Based on the DMAIC decision-making cycle, the role of MES in continuous improvement can be illustrated. The first steps are defining metrics and measuring them. A system that continually improves, relies on feedback. Due to its real-time data availability, MES is seen as the best tool to measure real-time performance indicators such as the use of materials, process times and machine breakdowns (Hwang 2006, Saenz et al. 2009). Typical operational Key Performance Indicators (KPI) reflect safety, customer service and cost factors such as overtime, inventory, utilization and quality (MESA 2006). The analysis phase requires human expertise and additional tools such as operational research and analytical methods. Process metrics (ex. OEE for equipment performance), analysis (ex. Pareto charts for machine breakdown causes) and reporting has become somewhat standard functionality within MES software applications. But the current literature lacks sufficient attention on how to make MES (or even information technology in general) support this analysis (Saenz et al. 2009). Efforts rarely exceed the use of spreadsheets or stand-alone software tools that require intensive human interaction. In fact, methods such as VSM are generally believed to be manual processes (Biddle 2006). But the real-time data availability and user friendliness of a MES can speed up and guide the analysis efforts. During the improvement phase, MES is naturally not involved. Except for the necessary improvement of MES itself to control the improved situation. To control the change, MES can standardize the new way of working by imposing standard work on the shop floor. 


\subsection{MES - the role of continuous improvement}

The main reason why the use of IT is feared by Lean practitioners is its tendency to become obsolete. Bell (2005) discusses the use of IT to maintain continuous improvement initiatives by also adapting the Enterprise IT system itself. From the point of view of the whole Lean Enterprise, Bell focuses on Enterprise Resource Planning (ERP) software. However, when considering Lean production, the combination with a Manufacturing Execution System (MES) seems more appropriate. A MES is located closer to production and is fine-tuned to the specific company needs. The usability of MES highly depends on its ability to reflect the current manufacturing situation. The continuous improvement of MES itself during the Lean journey is important to keep the system reliable. A MES should always present the data wished for by the user, at the right format, at the right time, at the right place. This application of the Lean philosophy to information technology is referred to as Lean Information Management (Hicks 2007). Recent literature acknowledges the need for a reconfigurable (Zhaohui et al. 2009) and adaptable (Gang et al. 2010) MES in order to follow manufacturing changes quickly and adequately. A MES should be flexible enough to follow the changes made as result of continuous improvement initiatives.

\section{Alignment method for MES and Lean}

Before implementing a MES, all processes - as well from the material as the information flow - must be critically reviewed to ensure an optimal workflow. Otherwise you just end up 'automating a mess'. That is why a thorough analysis is needed before selecting and configuring the software. By modeling the AS-IS situation, everyone is forced to question the current way of working. Problems get discovered and inefficiencies revealed, resulting in a TO-BE situation. Lean practitioners strongly suggest a manual Lean transformation before IT adoption (Masson and Jacobson 2007). But at which point can you switch from manual to IT? When your processes are perfect and won't change anymore? Lean is a continuous improvement process, so that situation will never occur. In addition, even early Lean efforts can benefit from IT support, in particular for data collection and analysis. As stated in section 2, some functionalities even require the support of IT, because they are too complex (ex. controlling WIP with high product mix and volatile demand) or simply enforced by legal provisions (ex. tracking \& tracing). So why not take both 
Lean and MES into account during the first analysis and take the best of both (Gifford 2002)? This approach could also have a positive impact on the Return On Investment (ROI) calculation, as the intangible benefits of IT are quite difficult to quantify (Nagalingam and Li 1997, Nasarwanji et al. 2009, Fraser 2009). The quick wins of the Lean transformation could help justify the initial investment cost of MES.

\subsection{Manufacturing Operations Management (MOM) analysis}

Manufacturing operations management gives a detailed overview of all the activities that support manufacturing in the area of production, inventory, maintenance and quality. As well MES as Lean activities can be classified within this framework.

\subsubsection{MES activities}

Saenz et al. (2009) describe the traditional internal structure of most MES solutions. They are designed on a modular basis, so each system can be configured and integrated as desired. As a consequence, the complexity of analyzing the manufacturing operations support needed for each manufacturing case is high and far from trivial. The contribution of the ISA 95 standard is only discussed briefly by Saenz et al. (2009) as the formalization of the exchange around the manufacturing system to other areas of the company. It's use is presented as the design of information flows between shop floor level applications and those of a higher level. In addition ISA 95 is stated to deliver a consistent terminology. Although these are in fact the main contributions, it's practical benefits reach a lot further and deserve some extra attention. ISA 95 part 1, $2 \& 3$ (ISA 2000) provide a number object models and terminology that serves as a common model of integration, a standard terminology to define system requirements and integration between different software systems. By mapping the existing manufacturing systems and tools on the models (AS-IS situation), filling the blanks with new systems, checking the integration needs and considering the different information flows, ISA 95 can be the roadmap for a well structured analysis. Based on the ISA 95 models, a blueprint of the TO-BE situation can be constructed. Scholten (2007) describes the procedure to construct a User Requirements Specification (URS) document. This document is used by consultants to clearly specify the requirements of the manufacturing company within the manufacturing operations domain. The result can be used in the selection procedure of the MES solution that best fits all needs. Figure 2 illustrates the use of the MOM 
framework to list the manufacturing operations support in a specific company situation (AS-IS).

\subsubsection{Lean activities}

The MOM definition is part of the ISA 95 standard and was mainly introduced to create a common ground to classify and compare existing MES software systems or integrate different components to seamlessly one solution. However, MOM provides a framework to classify all manufacturing operations, disregarded the fact whether they are performed manually or automated. Therefore, the framework can also be used to classify the support for Lean practices and as consequence check the possible alignment between MES components and Lean practices (Cottyn et al. 2008, Cottyn et al. 2009). This is the foundation of the proposed alignment within this paper. Figure 3 illustrates how the Lean practices can be marked onto the MOM framework. A nonrestrictive amount of examples is given.

\subsection{Alignment method}

The MES functionalities and Lean practices can be mapped onto the same MOM framework for a specific company situation. This makes it possible to check the necessary information flow (support) in between all components during the MOM analysis. By zooming into a certain functionality, the required information flows can be identified in more detail. All information flows consist of standard object models, as defined by ISA 95 part 1, $2 \& 3$ (ISA 2000). Figure 4 shows the alignment method for a brown- and greenfield project. A brownfield project has historical information at the start, while a greenfield project hasn't. The available information is standardized to ISA 95 object models to enable a generic MOM analysis. The result of the complete exercise is an alignment between MES and the selected Lean practices in the work plan. In a greenfield project, the support is incorporated in the requirements analysis. A change management approach is necessary within a brownfield project.

Value stream mapping - a crucial Lean practice at the start of the Lean journey - is explored as an example. Until recently, VSM has generally been a manual process (Biddle 2006). It is based on five phases put into practice by a special team created for such a purpose (Rother and Shook 1999): (1) Selection of a product family; (2) Current state mapping; (3) Future state mapping; (4) Defining a work plan; 
(5) Achieving the work plan. Similarities between product workflows are searched to define product families. The necessary data are collected by walking through the production process. The current state map is drawn with paper and pencil. After analysis, a future state map and a Lean transformation plan is created. Following up the Lean progress is done by continuously repeating the data collection and drawing steps. However, this approach has a number of limitations:

- It is time and labor consuming. It takes a while to walk through the whole process and collect all necessary data.

- The result is only a snapshot of the real value stream and can lead to poor decisions.

- The manual process is prone to different kinds of errors: process interpretation faults, wrong measurements, writing or reading errors, vague estimates, etc.

- The manual drawing of the current and future state can be sloppy and cause misinterpretation within the team.

- The operational threshold is very high. The data collection won't be done frequently due to the high time and labor intensity. That can cause an inefficient follow-up of the progress and - as a consequence - an inability to react to unforeseen circumstances. An insufficient follow-up makes it hard to sustain the continuous improvement initiatives.

The use of IT can increase the practical performance of VSM (Serrano et al. 2008). There are electronic tools available that allow a better representation of the maps, support the analysis and document and visualize the progress. They are called electronic value stream mapping (eVSM) tools and are mostly based on spreadsheets. Another recent evolution is the combination of VSM with discrete event simulation to analyze and evaluate the current and future states (Lian and Van Landeghem 2007). After a simulation run, the potential impact of the proposed modifications can be measured. This allows the team to make changes and observe the effects without disrupting the production process or causing downtime and costs. But the main effort, namely collecting the data, remains purely manual.

A good alignment with a MES - where a lot of data is already available could speed up this process. We are not suggesting a tool to automatically perform the construction and analysis of VSM. But MES can deliver meaningful information to generate an eVSM template to start from or to be used to validate the manual result. 
When the information from MES doesn't match the manual result, then something is wrong. As well a wrong manual exercise as information errors in MES are not acceptable and must be corrected somehow. Figure 5 shows part of the MOM framework that is useful in the case of VSM, which is contained within (or connected to) the performance analysis. Useful information for the construction (or validation) of the value stream map are the different incoming arrows. Possible input from MES can be:

- Identifying product families

- Creating part of the AS-IS process flow

- Creating part of the AS-IS information flow

All information can be identified through standard ISA 95 object models. Activity definitions are described by process segment object models. The actual use of those processes is delivered by segment response object models. Based on that information, the different VSM atoms can be connected together to form the material and information value stream. The corresponding performance information can be added as KPI's on the map.

\section{Case example: a furniture company}

To illustrate the use of the alignment method, a case example is performed within a small ( $<50$ employees) furniture company. There is (limited) production support by software tools in the AS-IS situation, so the case is treated as a brownfield project.

\subsection{Map the AS-IS situation}

\subsubsection{Information flow}

The current manufacturing operations support is shown in Figure 6 and consists of:

- MS Excel: The production manager creates a production schedule once a week. Internal quality problems are kept in another Excel file.

- Barcode scanning: The start of each activity on an order by an employee is recorded through barcode scanning.

- Paper based: Work orders and product definitions are distributed by the production manager based on the schedule. Once or twice a day the progress is measured by revisiting each work center. Quality checks are indicated on the work orders and results are written down by the employees.

- MS Access: Customer complaints are logged into a custom application.

- Custom ERP system: Accounting, procurement of raw materials, order processing, etc. 
Most of the above functionality was introduced in the past to be able to calculate some Key Performance Indicators (KPI). Each month the manager retrieves information from the different systems and calculates the KPI values with MS Excel.

- Number of seats produced

- Efficiency of employee or work center

- Leather consumed

- Number of internal reparations

- Number of external complaints

Based on the scanning results, the theoretical production time of each step within ERP is regularly modified (manually). This is done to actualize cost calculation for the different models and can be used as starting value for a comparable production activity for new models.

\subsubsection{Material flow}

The available historical data (6 months of production) are mapped onto ISA 95 object models. To generate a starting template for eVSM, the same steps are performed as in the manual case. All end products have a similar production path (production definition), so they are combined to one product family. The map is drawn in opposite direction of the value stream itself. The last step of the VSM is the process segment of which the corresponding segment responses have the final product(s) of the product family as 'Material Produced Actual'. Then, for each 'Material Consumed Actual' of that segment response, the next process segment (with that material type as 'Material Produced Actual') is drawn in front of the previous one. These steps must be repeated until the beginning of the value stream, namely receiving the raw materials. The selected values to be added to the map are the number of employees and the mean cycle time of each activity (the duration is recorded by the barcode scanning). The time that each product stays in inventory is not exactly known, but is expressed in a mean number of days (date of next activity - date of previous activity). The eVSM template of figure 7 can be used as starting document for the manual effort or later on used for validation purposes.

\subsection{Map the TO-BE situation}

On one hand the company wants to upgrade and simplify their manufacturing operations (information flow). On the other hand, they want to optimize production performance by reducing the work in process (and by doing so, reducing the product 
lead time) and creating a higher manufacturing visibility. Figure 8 shows the desired software landscape. In a first phase all production support must be incorporated by a paperless MES system. The production manager gets the released orders from ERP and must be able to launch orders on the shop floor. Each work center has a touch panel with an overview of its waiting list of orders. Through simple screen actions, employees can indicate which order they start. They get electronic information about the required materials and actions. When finished they are guided through some quality checks and can forward the order to the next step. Based on this information, the monthly desired key performance indicators are calculated in real-time for the manager. In a second step, a small Warehouse Management System (WMS) will be implemented to control the stock of raw materials.

\subsection{Create a Lean work plan}

To start the Lean journey, $5 S$ will be introduced on the shop floor. In addition a Visual Management screen will keep all employees informed about the production performance (ex. Seats/day, quality problems/week, etc.). In order to reduce the work in process, a CONWIP system will be initiated. The number of orders on the production floor will be limited. Each time an order is finished, the production manager can launch a new one. To optimize the production activities, each work center will prioritize its waiting orders.

- The cutting process will group the available orders based on the colour. That will minimize the changeover times.

- The sticking process will group orders with similar actions, because employees prefer repetitive actions (and perform better this way).

- The covering process will group orders according to the region of the customer. This approach must minimize the waiting times of the end products to be transported to the customer.

This strategy will be initiated based on the historical data and later on fine-tuned depending on the performance. The different practices will be implemented in a phased approach (Figure 9).

\subsection{Align MES with Lean}

When considering the overlap of Lean and MES activities in the MOM framework, the MES system must be configured to support the Lean practices. A few examples:

- Each work center must have a user-friendly screen that enables the employees to easily assess the priority of each order. For example, at the cutting process, 
each order is listed (and marked) depending on its colour. The information at the covering process contains the region of the customer. At the stitching process a similarity percentage of each order can be given.

- The CONWIP restriction must be enforced. However, the production manager must have the authority to fine-tune this value.

- The manager must have access to a dashboard screen containing all KPI values and trends. Some values are displayed within the production hall to inform and stimulate the employees.

- The time registration at each work center must reveal the value-adding time. A proper use of the system must be enforced by logical and fixed user screens. The production manager must be informed of eventual abnormalities.

- The performance information can be used at a later stage to redraw a basic eVSM document and re-analyze the situation.

Based on this requirements, the MES system must be configured. However, MES must follow process improvements and must be reconfigured to control the change.

\section{Conclusion and Further Research}

Different kinds of software tools can analyze real-time data and turn them into valuable knowledge to optimize manufacturing operations. However, the difficulty of integrating multiple point systems has brought software providers to package multiple execution management components into single and integrated solutions. These systems, commonly referred to as Manufacturing Execution System (MES), provide a common user interface and data management system. An alignment method between a Manufacturing Execution System (MES) and Lean objectives is introduced within this work. MES can provide the necessary support during the Lean journey. MES can trigger, feed or validate the Lean decision making process by providing useful information. In addition, MES can maintain the process improvements by enforcing the standardized way of working. However, this is only possible when MES is aligned and is kept aligned to the Lean objectives. By mapping the activities of both on the Manufacturing Operations Management (MOM) framework of ISA 95, a common ground can be identified. In brownfield projects, historical data are available to create a template to start or to validate a manual Value Stream Map (VSM). Greenfield projects start from scratch. By structuring the information as ISA 95 object models, a generic analysis is possible. After analysis a TO-BE MOM situation can be drawn, which stipulates the necessary requirements for the MES selection and implementation. In order to illustrate the methodology, a case example of a small furniture company is explored. Further research has to be done on a change 
management approach for MES that facilitates the model state changes as result of typical Lean transformations. The impact of the proposed alignment on the Return On Investment (ROI) calculations can also be worthwhile. 


\section{References}

Abdulmalek, F.A. and Rajgopal, J., 2007.Analyzing the benefits of Lean manufacturing and value stream mapping via simulation: A process sector case study. International Journal of Production Economics 107, 223-236.

AberdeenGroup, inc., 2005. Manufacturing Transparency: Turning Visibility into Value [online]. AberdeenGroup inc. Available from: http://www.acumence.com/pdf/AberdeenTransparency.pdf [Accessed 10 January 2009].

Bell, S., 2005. Lean Enterprise Systems: Using IT for Continuous Improvement. Wiley. ISBN: 978-0-471-67784-0.

Biddle, J., 2006. The Lean Benchmark Report [online]. AberdeenGroup inc. Available from: http://www.aberdeen.com/Aberdeen-Library/2845/RA_Lean_JB_2845. aspx [Accessed 10 January 2009].

Braglia, M., Carmignani, G. and Zammori, F., 2006. A new value stream mapping approach for complex production systems. International Journal of Production Research, 44 (18), 3929 - 3952.

Cottyn, J., Stockman, K., Van Landeghem, H., 2008. The Complementarity of Lean Thinking and the ISA 95 standard. In: Proc. of WBF European Conference: Bridging the Divide between IT and Manufacturing, Barcelona (Spain).

Cottyn, J., Van Landeghem, H., Stockman, K., Derammelaere, S., 2009. The combined adoption of production IT and strategic initiatives: Initial considerations for a Lean MES analysis, In: Proc. of International Conference on Computers \& Industrial Engineering, 39, 1629 - 1634.

Duque, F.M.D. and Cadavid, L.R., 2007. Lean manufacturing measurement: The relationship between Lean activities and Lean metrics, Estudios Gerenciales, 23 (105), 69-83.

Epicor, 2008a. How manufacturers are managing business in turbulent economic times [online]. Epicor Software Corporation. Available from: http://www.nelsonequipment.com/newsletters/Epicor_Manufacts_ManageBusi Mana.pdf [Accessed 10 January 2009].

Epicor, 2008b. Designed to Manage Lean Principles [online]. Epicor Software Corporation. Available from: http http://www.nambuyersguide.com/WSWeb/WAND_attachment.asp?mfg_code $=50640069 \&$ iFile_ID=1300 [Accessed 15 January 2009]. 
Fraser, J., 2009. Plant-to-Enterprise Integration: Foundation for MES/MOM Payback [online]. Cambashi. Available from: http://www.cambashi.com/content1278 [accessed 10 January 2010].

Gang, H., Jinhang, L. and Xiaodong, Y., 2010. Developing an Adaptable Manufacturing Execution System Framework, In: Proceedings of the 6th CIRP-Sponsored International Conference on Digital Enterprise Technology, 66, 749-756.

GE FANUC, Intelligent Platform, 2009. Lean Production with Work Process [online].

ISA. Available from: http://www.graymattersystems.com/Docs/Products/ProficyWorkflow/lean_pro duction_work_process_wp_gft738a.pdf [Accessed 20 february 2009].

Gifford C. H., 2002. 'LEAN' or MES? To optimize, take best of both [online]. ISA. Available from: http://www.isa.org/InTechTemplate.cfm?Section=InTech\&template=/Content Management/ContentDisplay.cfm\&ContentID=20074 [Accessed 20 November 2008].

Goddard, R.W., 2003. The Role of Information Technology in the Lean Enterprise.

Hicks, B., 2007. Lean Information Management: Understanding and Eliminating Waste. International Journal of Information Management, 27, 233-249.

Hines, P., Holweg, M., Rich, N., 2004. Learning to evolve: A review of contemporary lean thinking. International Journal of Operations \& Production Management, 24 (10), 994-1011.

Houy, T., 2005. ICT and Lean Management: Will They Ever Get Along? Communications \& Strategies, 59, 53-75.

Hwang, Y.-D., 2006. The practices of integrating manufacturing execution systems and Six Sigma methodology. International Journal of Advanced Manufacturing Technologies, 31, 145-154.

ISA 95, 2000. Enterprise-control system integration, ANSI/ISA 95.00.01 part 1 : Models and terminology ; ANSI/ISA 95.00.02 part 2 : Object model attributes, Raleigh, North Carolina, USA.

Lasa, I.S., De Castro, R. and Laburu, C.O., 2009. Extent of the use of Lean concepts proposed for a value stream mapping application. Production Planning \& Control, 20 (1), 82-98. 
Lian, Y.-H., Van Landeghem, H., 2007. Analyzing the effects of Lean manufacturing using a value stream mapping-based simulation generator, International Journal of Production Research, 45 (13), 3037-3058.

Masson, C. and Jacobson, S., 2007. Lean Planning and Execution Software: Extending Lean Thinking Across the Enterprise [online]. AMR Research Available from: http://www.amrresearch.com/Content/View.aspx?CompURI=tcm:7-18992 [accessed 14 January 2009]

Mazur, L.M. and Chen, S.-J. G., 2008. Understanding and Reducing the Medication Delivery Waste Via Systems Mapping and Analysis. Health Care Management Science, 11, 55-65.

Mejabi, O.O., 2003. Framework for a Lean manufacturing planning system, International Journal of Manufacturing Technology and Management, 5(5/6), 563-578.

MESA, 1997. White Paper \#02: MES Functionalities and MRP to MES Data Flow Possibilities [online]. MESA International. Available from: http://www.mesa.org/knowledge-base/details.php?id=49 [Accessed 8 November 2008].

MESA, 2006. Metrics that matter: Uncovering KPIs that justify operational improvement [online]. MESA International and Industry Directions. Available from: http://www.mesa.org/knowledge-base/details.php?id=5 [Accessed 8 November 2008].

MESA, 2008. Plant to Enterprise model [online]. Available from: http://www.mesa.org/knowledge-base [Accessed 18 November 2009].

MESA, 2010. Guidebook Lean Manufacturing [online]. Available from: http://www.mesa.org/knowledge-base [Accessed 18 September 2010].

Nagalingam, S.V. and Lin G.C., 1997. A unified approach towards CIM justification. Computer Integrated Manufacturing Systems, 10 (2), 133-145.

Nasarwanji, A., Pearce, D., Khoudian, P. and Worcester, R., 2009. The Impact of Manufacturing Execution Systems on Labor Overheads. In: Proceedings of the World Congress on Engineering Vol I.

Nash, M.A. and Poling, S.R., 2008. Mapping the Total Value Stream - A Comprehensive Guide for Production and Transactional Processes, New York: Productivity Press. 
Pavnaskar, S.J., Gershenson, J.K., Jambekar, A.B., 2003. Classification scheme for Lean manufacturing tools. International Journal of Production Research, 41 (13), 3075-3090.

Pfadenhauer, K., Kittl, B., Dustdar, S., Levy, D. Shop Floor Information Management and SOA. BPM 2006 Workshops, LNCS 4103, 237-248.

Ray, C. D., Zuo, X., Michael, J. H., and Wiedenbeck, J. K., 2006. The Lean Index: Operational "LEAN" Metrics for the Wood Products Industry. Wood and Fiber Science, 38 (2), 238-255.

Riezebos, J., Klingenberg, W. and Hicks, C., 2009. Lean Production and information technology: Connection or contradiction?, Computers in Industry, 60 (4), 237-247.

Rio, R., 2005. Accelerated Continuous Improvement: Getting to Program Impact [online]. ARC Advisory Group. Available from: http://www.arcweb.com/ClientSponsored/Accelerated\%20Continuous\%20Imp rovemeIm.pdf [Accessed 12 January 2009].

Rother, M., Shook, J., 1999. Learning to See: Value Stream Mapping to Add Value and Eliminate Muda, Brookline, MA: The Lean Enterprise Institute, Inc.

Saenz de Ugarte, B., Artiba, A., and Pellerin, R., 2009. Manufacturing execution system - a literature review. Production Planning \& Control 20 (6), 525-539.

Scholten, B., 2007. The road to integration: A guide to applying the ISA-95 standard in manufacturing. ISA.

Serrano, I., Ochoa, C. and Castro, R., 2008. Evaluation of value stream mapping in manufacturing system redesign, International Journal of Production Research, 46 (16), 4409-4430.

Shah, R. and Ward, P.T., 2003. Lean manufacturing: context, practice bundles, and performance. Journal of Operations Management, 21, 129-149.

Shah, R. and Ward, P.T., 2007. Defining and Developing Measures of Lean Production. Journal of Operations Management, 25, 785-805.

Siemens, Industry Solutions, 2007. Plant IT Integration for Collaborative Manufacturing. Available from: http://www.itsolutions.siemens.com/b2b/it/en/us/Documents/whitepapers/Plant-ITIntegration-WP.pdf [Accessed 12 January 2009]. 
Smith, B., 2003. Lean and Six Sigma - A One-Two Punch, Quality Progress, 36 (4), 37-41.

Wan, H.-d., and Chen, F. F. A, 2007. Web-based Kanban system for job dispatching, tracking, and performance monitoring. International Journal of Advanced Manufacturing Technologies, 38 (9-10), 995-1005.

Ward, P., and Zhou, H., 2006. Impact of Information Technology Integration and Lean/Just-In-Time Practices on Lead-Time Performance. Decision Sciences, 37 (2), 177-203.

Womack, J.P., Jones, D.T., and Roos, D., 1990. The machine that changed the world. Toronto, Canada: Collier MacMillan ISBN 0892563508.

Womack, J.P. and Jones D.T., 1996. Lean Thinking. New York: Simon \& Schuster.

Zhaohui, L., Yan, C., Xiuquan, C., 2009. A Reconfigurable Manufacturing Execution System and its Component Reuse, In: Proceedings of International Conference on Computational Intelligence and Natural Computing, 2, 190193. 
Figure 1. Creating business and manufacturing visibility to support the continuous improvement cycle

Figure 2. Example of the use of the MOM framework to list the manufacturing operations support

Figure 3. Example of the use of the MOM framework to list the Lean practices

Figure 4. The alignment method between MES and Lean for brown- and greenfield projects

Figure 5. Detail of the MOM framework in the case of Value Steam Mapping Figure 6. The MOM support in the AS-IS situation of the case example

Figure 7. The automatically generated eVSM template of the case example

Figure 8. The TO-BE situation of software landscape of the case example

Figure 9. The phased approach of the Lean transformation of the case example 


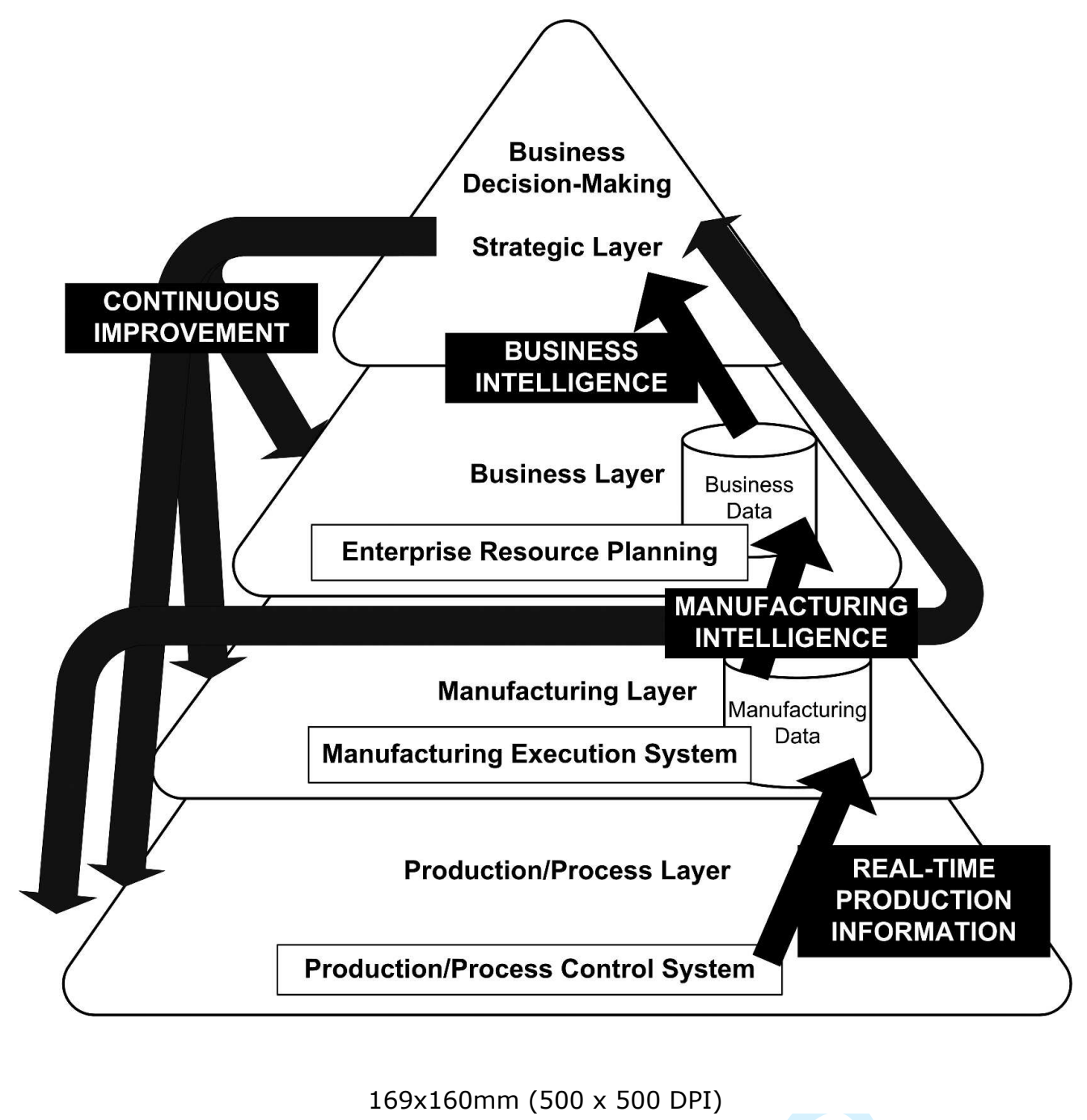




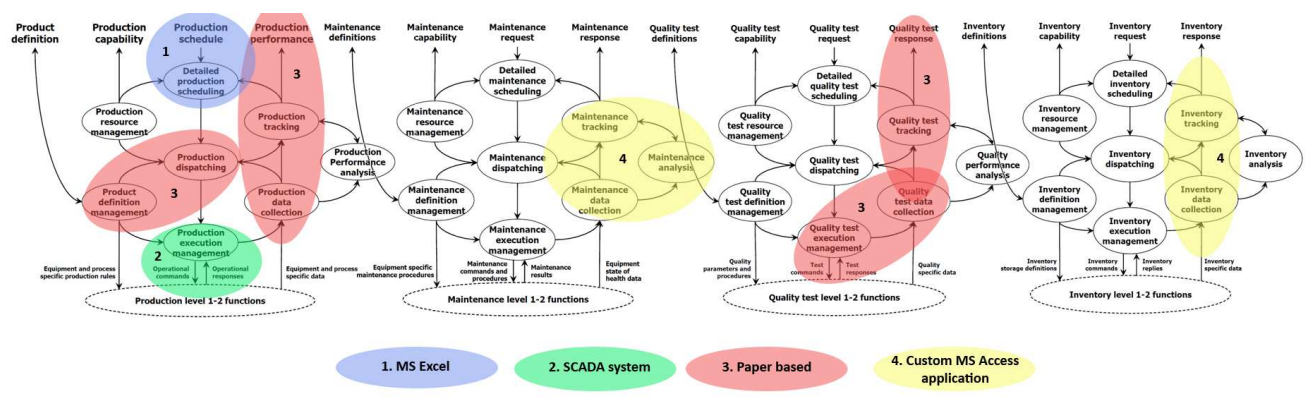

$156 \times 50 \mathrm{~mm}(300 \times 300 \mathrm{DPI})$ 


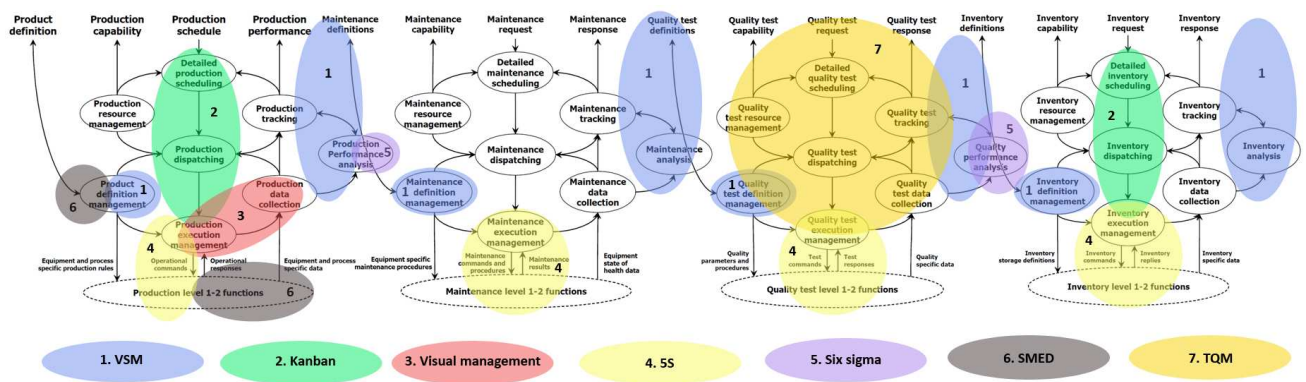

$156 \times 50 \mathrm{~mm}(300 \times 300 \mathrm{DPI})$ 


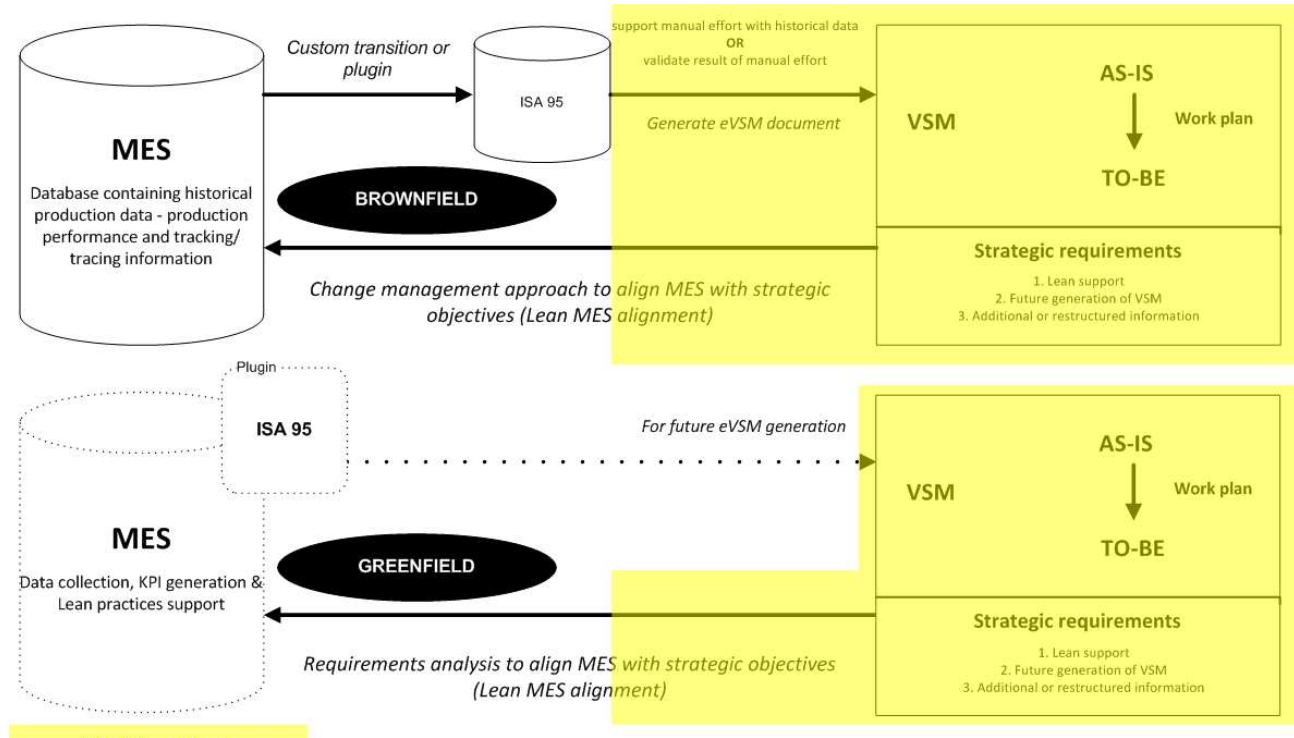

MOM analysis

$101 \times 60 \mathrm{~mm}(300 \times 300 \mathrm{DPI})$ 


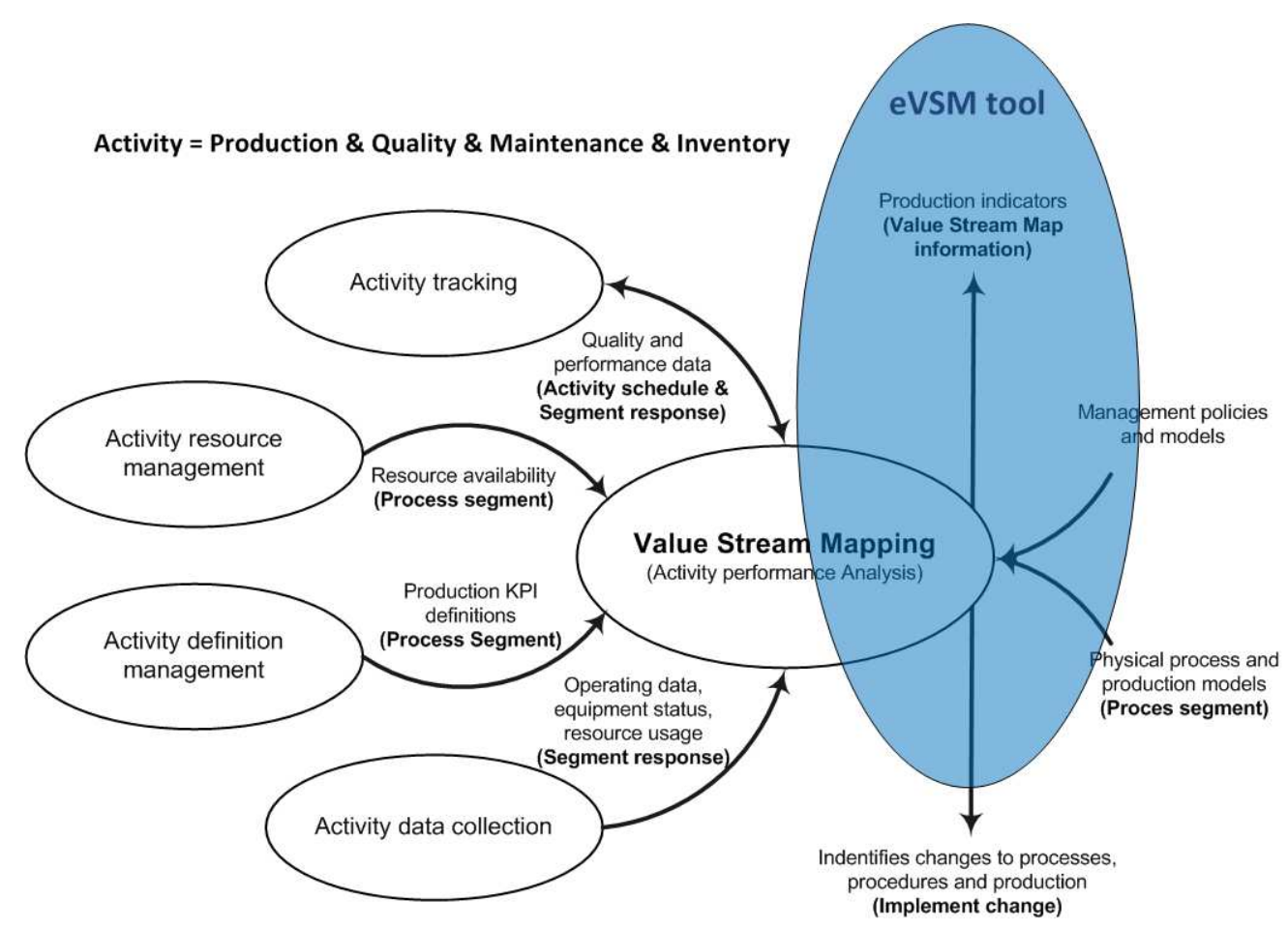

$88 \times 62 \mathrm{~mm}(300 \times 300$ DPI $)$ 


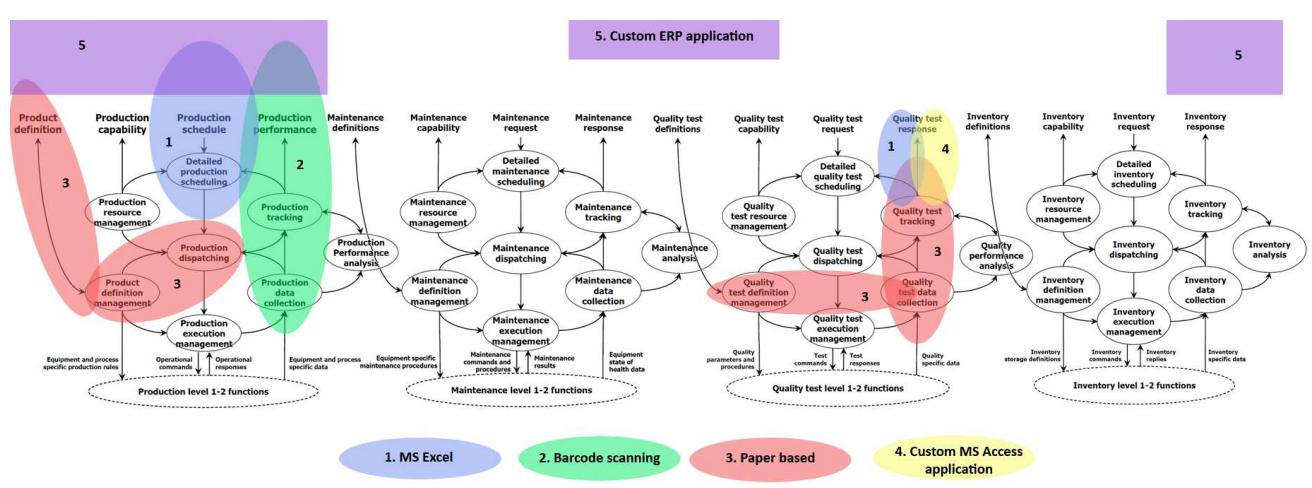

$156 \times 60 \mathrm{~mm}(300 \times 300 \mathrm{DPI})$ 


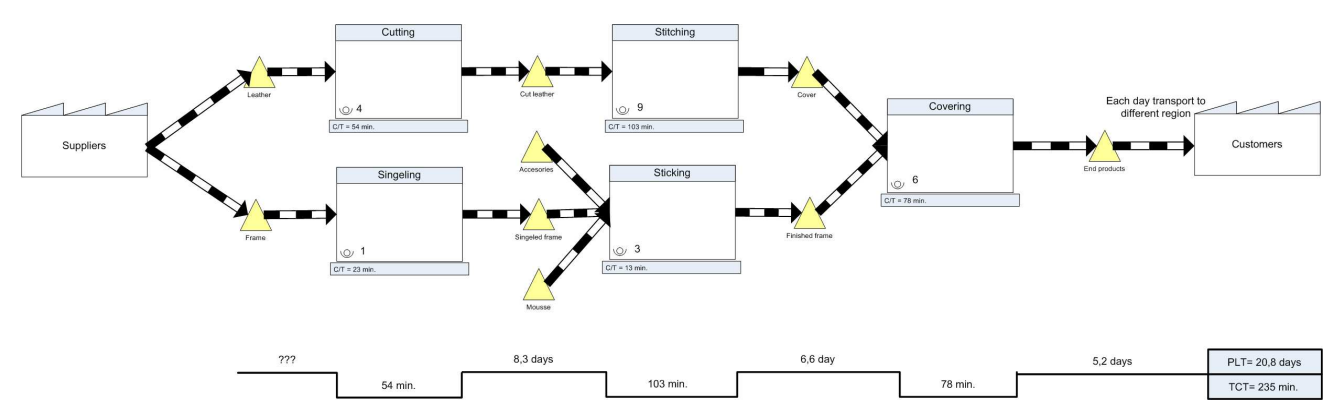

$210 \times 60 \mathrm{~mm}(300 \times 300 \mathrm{DPI})$ 


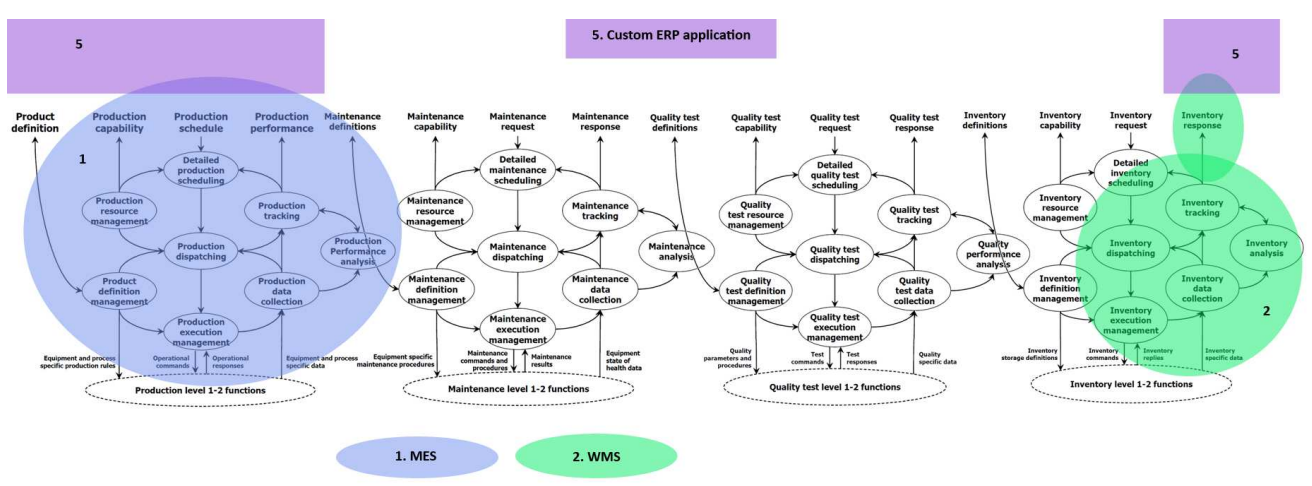

$156 \times 60 \mathrm{~mm}(300 \times 300 \mathrm{DPI})$ 


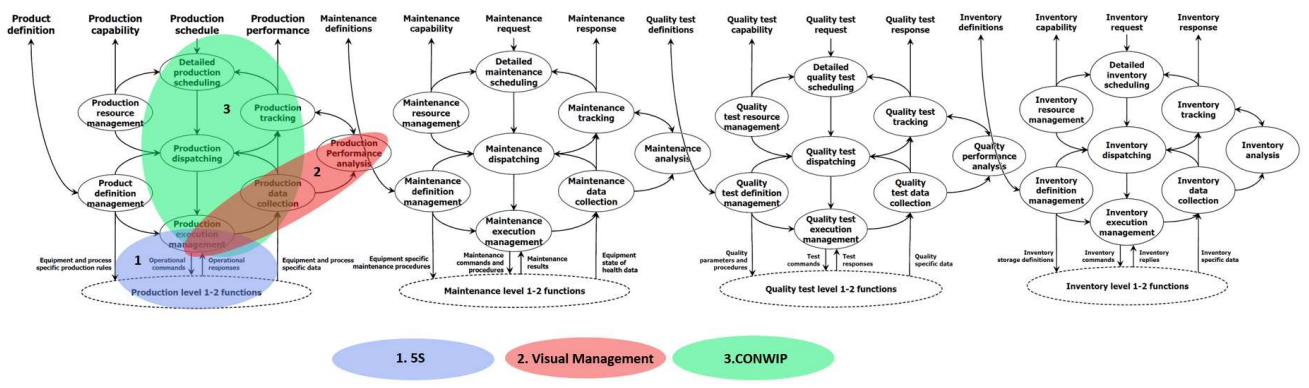

$156 \times 60 \mathrm{~mm}(300 \times 300 \mathrm{DPI})$

http://mc.manuscriptcentral.com/tprs Email: ijpr@lboro.ac.uk 